\title{
Normal values of aortic dimensions, distensibility, and pulse wave velocity in children and young adults: a cross-sectional study
}

Inga Voges ${ }^{1 \dagger}$, Michael Jerosch-Herold ${ }^{3 \dagger}$, Jürgen Hedderich², Eileen Pardun ${ }^{1}$, Christopher Hart ${ }^{1}$, Dominik Daniel Gabbert ${ }^{1}$, Jan Hinnerk Hansen ${ }^{1}$, Colin Petko ${ }^{1}$, Hans-Heiner Kramer ${ }^{1+}$ and Carsten Rickers ${ }^{{ }^{*+}}$

\begin{abstract}
Background: Aortic enlargement and impaired bioelasticity are of interest in several cardiac and non-cardiac diseases as they can lead to cardiovascular complications. Cardiovascular magnetic resonance (CMR) is increasingly accepted as a noninvasive tool in cardiovascular evaluation. Assessment of aortic anatomy and bioelasticity, namely aortic distensibility and pulse wave velocity (PWV), by CMR is accurate and reproducible and could help to identify anatomical and bioelastic abnormalities of the aorta. However, normal CMR values for healthy children and young adults are lacking.
\end{abstract}

Methods: Seventy-one heart-healthy subjects (age $16.4 \pm 7.6$ years, range $2.3-28.3$ years) were examined using a 3.0 Tesla CMR scanner. Aortic cross-sectional areas and aortic distensibility were measured at four positions of the ascending and descending thoracic aorta. PWV was assessed from aortic blood flow velocity measurements in a aortic segment between the ascending aorta and the proximal descending aorta. The Lambda-Mu-Sigma (LMS) method was used to obtain percentile curves for aortic cross-sectional areas, aortic distensibility and PWV according to age.

Results: Aortic areas, PWV and aortic distensibility (aortic cross-sectional areas: $r=0.8$ to $0.9, p<0.001 ; P W$ : $r=0.25$ to $0.32, p=0.047$ to 0.009 ; aortic distensibility $r=-0.43$ to $-0.62, p<0.001$ ) correlated with height, weight, body surface area, and age. There were no significant sex differences.

Conclusions: This study provides percentile curves for cross-sectional areas, distensibility and pulse wave velocity of the thoracic aorta in children and young adolescents between their $3^{\text {rd }}$ and $29^{\text {th }}$ year of life. These data may serve as a reference for the detection of pathological changes of the aorta in cardiovascular disease.

\section{Background}

The thoracic aorta plays an important role in the cardiovascular system. It's elastic buffering capacity transforms the pulsatile effect caused by ventricular ejection into a continuous blood flow [1,2]. In children and young adults several cardiac and non-cardiac diseases manifest themselves by aortic enlargement and impaired aortic bioelastic function [3-6]. These changes may be of clinical relevance as they can lead to cardiovascular

\footnotetext{
* Correspondence: rickers@pedcard.uni-kiel.de

${ }^{\dagger}$ Equal contributors

'Department of Congenital Heart Disease and Pediatric Cardiology, University Hospital of Schleswig-Holstein, Campus Kiel, Arnold-Heller-Str. 3, 24105, Kiel, Germany

Full list of author information is available at the end of the article
}

complications such as left ventricular dysfunction [7], aneurysm formation, atherosclerosis, myocardial infarction and stroke [8-10] in later life.

Aortic distensibility and aortic pulse wave velocity (PWV) are two parameters closely related to the bioelastic function of the aorta and serve as pathogenic markers in cardiovascular disease [11]. Quantification of aortic distensibility and PWV by cardiovascular magnetic resonance (CMR) has been shown to be accurate and reproducible and could help in identifying early cardiovascular disease in asymptomatic patients $[1,12,13]$.

However, reference ranges from childhood to adulthood are lacking. Therefore we sought to establish CMR normal ranges of aortic distensibility and aortic PWV as 
well as of aortic cross-sectional areas in heart-healthy children and young adults.

\section{Methods}

\section{Study population}

71 children and young adults aged 2.3 - 28.3 years underwent a CMR study for the assessment of aortic dimensions, distensibilty and PWV. Table 1 shows the sex and age distribution of the total study group.

The study participants were recruited among medical students and healthy children of hospital staff. Five children were recruited from the department of pediatric neurology. They underwent diagnostic magnetic resonance imaging (MRI) of the central nervous system (CNS) because of psychomotor retardation and epilepsy. Immediately after CNS MRI, non-contrast enhanced CMR was performed. All study subjects were free from cardiovascular disease. During the study, heart rate, respiratory motion, oxygen saturation and non-invasive blood pressure were monitored.

The study protocol was approved by the local research ethics committee and conformed to the principles outlined in the Declaration of Helsinki. Written informed consent was obtained from participants older than 17 years and all persons responsible for care and custody of the child.

\section{Image acquisition}

All CMR studies were performed with a 3.0 Tesla CMR scanner (Achieva 3.0 T, Philips Medical Systems, Netherlands) using a phased-array coil for cardiac imaging (SENSE ${ }^{\mathrm{TM}}$ Cardiac coil, Philips Medical Systems, Netherlands).

Gradient echo cine CMR with retrospective gating was applied to assess aortic cross-sectional areas, which were used to describe the normal dimensions of the aorta and for distensibility calculation. We collected axial and coronal stacks of parallel, contiguous, views perpendicular to the aortic axis. The scan parameters were as follows: $280 \times 224 \mathrm{~mm}$, voxel size (read-, phase-encoding, and slice directions) $1.88 \times 1.94 \times 6 \mathrm{~mm}, \mathrm{TR} / \mathrm{TE}=4.4 \mathrm{l}$

Table 1 Sex and age distribution of the study group

\begin{tabular}{lllllllll}
\hline & & \multicolumn{6}{c}{ Age classes (years) } & Total \\
\cline { 2 - 8 } & & $\mathbf{- 5}$ & $\mathbf{5 - 1 0}$ & $\mathbf{1 0 - 1 5}$ & $\mathbf{1 5 - 2 0}$ & $\mathbf{2 0 - 2 5}$ & $\mathbf{2 5 - 3 0}$ & \\
\hline Sex male & $\mathrm{n}$ & 2 & 10 & 7 & 2 & 6 & 3 & 30 \\
& $\%$ & $6.7 \%$ & $33.3 \%$ & $23.3 \%$ & $6.7 \%$ & $20.0 \%$ & $10.0 \%$ & $100.0 \%$ \\
\multicolumn{1}{c}{ female } & $\mathrm{n}$ & 2 & 7 & 7 & 6 & 11 & 8 & 41 \\
& $\%$ & $4.9 \%$ & $17.1 \%$ & $17.1 \%$ & $14.6 \%$ & $26.8 \%$ & $19.5 \%$ & $100.0 \%$ \\
Total study & $\mathrm{n}$ & 4 & 17 & 14 & 8 & 17 & 11 & 71 \\
group & $\%$ & $5.6 \%$ & $23.9 \%$ & $19.7 \%$ & $11.3 \%$ & $23.9 \%$ & $15.5 \%$ & $100.0 \%$ \\
\hline
\end{tabular}

$2.5 \mathrm{~ms}, 25$ cardiac phases, no inter-slice gap, nonbreath-hold, number of repetitions: 2, scan duration: 3-6 min.

Phase-contrast cine CMR was performed to evaluate aortic PWV and to quantify aortic flow. PWV was assessed in a segment including the ascending aorta, the aortic arch and the proximal descending aorta up to the level of the pulmonary artery bifurcation (Figure 1). The slice plane intersected the ascending aorta at the sinutubular level, and the proximal descending aorta, both at an approximately right angle. Imaging parameters were

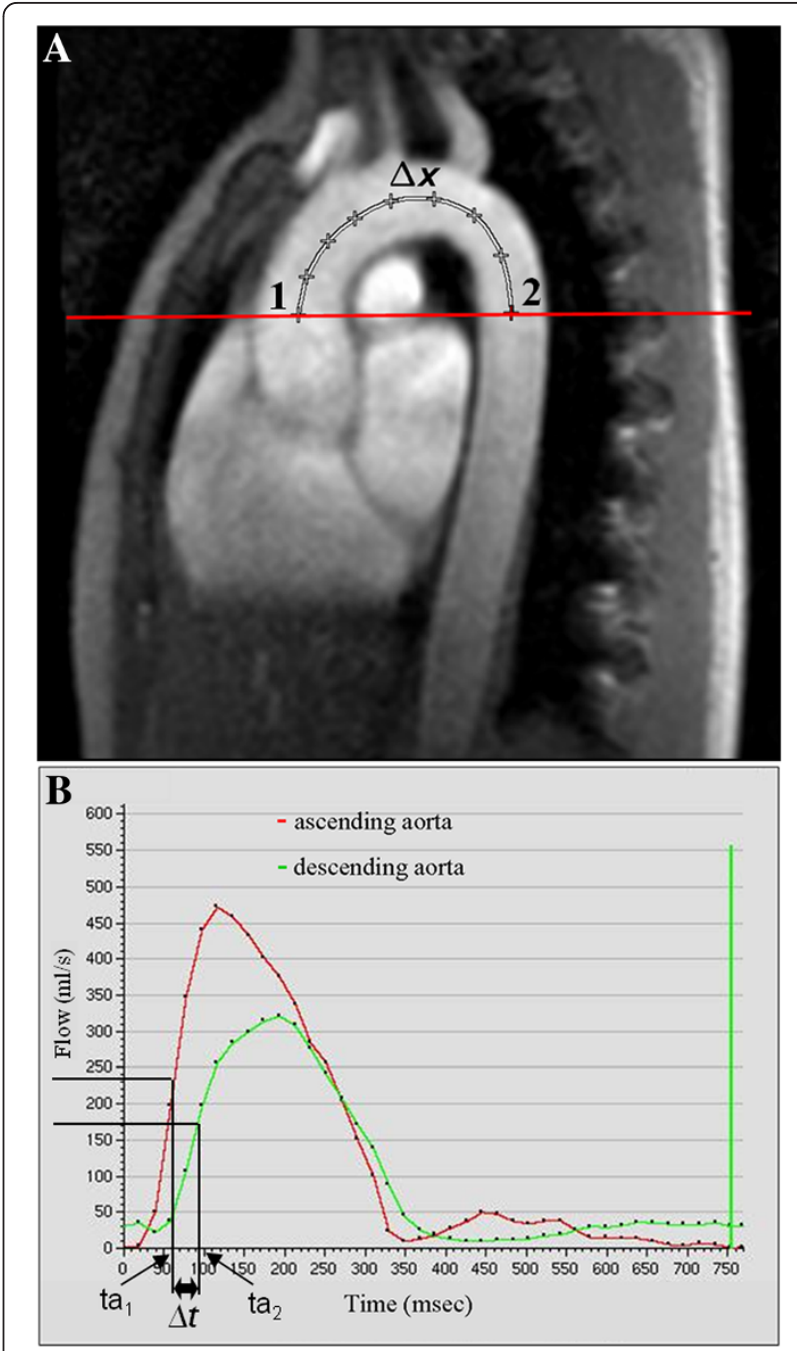

Figure 1 Aortic PWV, A) Sagittal CMR image that shows the sites where phase contrast cine images were acquired: 1) ascending aorta, 2) descending aorta. The distance between both locations $(\Delta \mathrm{x})$ was measured along a midline through the aortic arch. B) This graph shows the transit delay $(\Delta t)$ of the systolic flow curves in the descending relative to the ascending aorta. The transit time $(\Delta t)$ was determined from the midpoints of the systolic up-slope (ta1 and ta2) on the flow versus time curves. The difference of ta for ascending (ta1) and descending aorta (ta2) locations defined $\Delta \mathrm{t}$. Pulse wave velocity was estimated as $\Delta \mathrm{x} / \Delta \mathrm{t}$. 


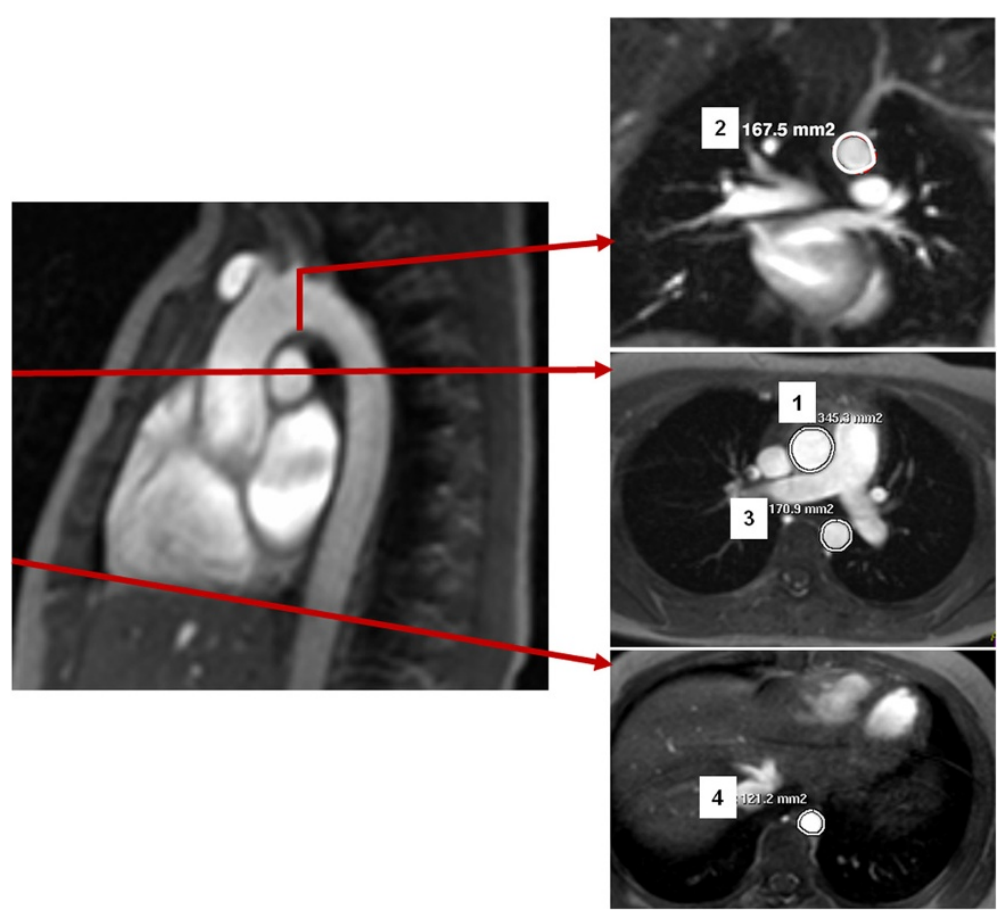

Figure 2 Cross-sectional aortic areas were assessed from axial and coronal CMR images at four different locations of the thoracic aorta: ascending aorta (1), transverse aortic arch (2), aortic isthmus (3), descending aorta above the diaphragm (4).

as follows: FOV $270 \times 270 \mathrm{~mm}$, voxel size $1.64 \times 1.4 \times$ $7 \mathrm{~mm}, \mathrm{TR} / \mathrm{TE}=4.4 / 2.7 \mathrm{~ms}, 40$ cardiac phases, velocity encoding $=200 \mathrm{~cm} / \mathrm{s}$. To determine the aortic segment length between the two aortic levels, sagittally angulated views of the aortic arch were acquired.

\section{Image analysis}

The images were analyzed with commercially available CMR software (ViewForum release 6.3, Philips Medical Systems, Netherlands).

Aortic cross-sectional areas were determined on axial and coronal gradient-cine images at four positions (Figure 2): ascending aorta, transverse aortic arch, aortic

Table 2 Mean blood flow and maximal flow velocity in the ascending aorta

\begin{tabular}{lcc}
\hline Age classes & Mean blood flow $(\mathbf{I} / \mathbf{m i n})$ & Maximal velocity $(\mathbf{c m} / \mathbf{s})$ \\
\hline-5 years & $2.8 \pm 0.1$ & $130.3 \pm 2.8$ \\
$5-10$ years & $3.9 \pm 0.8$ & $131.8 \pm 18.3$ \\
$10-15$ years & $4.4 \pm 0.9$ & $119.7 \pm 15.8$ \\
$15-20$ years & $6.1 \pm 1.4$ & $111.9 \pm 23.7$ \\
$20-25$ years & $5.6 \pm 1.1$ & $121.0 \pm 16.0$ \\
$25-30$ years & $5.5 \pm 1.2$ & $118.5 \pm 23.9$ \\
\hline
\end{tabular}

Data are expressed as mean and standard deviation. isthmus and descending aorta above the diaphragm. All measurements were made at the time of the maximal distension of the aorta. Aortic cross-sectional areas were preferred compared to diameters, because the aorta is not necessarily circular in all segments.

Aortic distensibility was measured from two-dimensional cine images in the ascending aorta, the transverse aortic arch and at two levels in the descending aorta.

Table 3 Characteristics of the study population

\begin{tabular}{|c|c|c|c|c|}
\hline Parameter & $\begin{array}{l}\text { Total study } \\
\text { group } \\
(\mathrm{n}=71)\end{array}$ & $\begin{array}{l}\text { Female } \\
\text { volunteers } \\
(n=41)\end{array}$ & $\begin{array}{l}\text { Male } \\
\text { volunteers } \\
(n=30)\end{array}$ & $\begin{array}{l}P \\
\text { value }\end{array}$ \\
\hline Age (years) & $16.4 \pm 7.6$ & $17.5 \pm 7.4$ & $14.9 \pm 7.7$ & 0.18 \\
\hline Weight (kg) & $50.9 \pm 21.9$ & $51.4 \pm 19.3$ & $50.2 \pm 25.1$ & 0.73 \\
\hline Height (cm) & $156.6 \pm 25.6$ & $157.5 \pm 23.0$ & $156.1 \pm 29.1$ & 0.86 \\
\hline $\mathrm{BSA}\left(\mathrm{m}^{2}\right)$ & $1.5 \pm 0.4$ & $1.5 \pm 0.4$ & $1.5 \pm 0.5$ & 0.84 \\
\hline $\mathrm{BMI}\left(\mathrm{kg} / \mathrm{m}^{2}\right)$ & $19.4 \pm 3.5$ & $19.7 \pm 3.4$ & $19.1 \pm 3.8$ & 0.57 \\
\hline $\mathrm{SBP}(\mathrm{mm} \mathrm{Hg})$ & $104.9 \pm 9.5$ & $103.7 \pm 9.3$ & $106.2 \pm 9.7$ & 0.48 \\
\hline $\mathrm{DBP}(\mathrm{mm} \mathrm{Hg})$ & $59.2 \pm 11.0$ & $58.8 \pm 10.9$ & $59.4 \pm 11.2$ & 0.91 \\
\hline $\mathrm{PP}(\mathrm{mm} \mathrm{Hg})$ & $45.7 \pm 8.4$ & $44.9 \pm 6.6$ & $46.8 \pm 10.4$ & 0.14 \\
\hline
\end{tabular}


Table 4 Cross-sectional areas, distensibility and PWV of the thoracic aorta by gender

\begin{tabular}{|c|c|c|c|c|}
\hline Parameter & $\begin{array}{l}\text { Total study group } \\
(\mathrm{n}=71)\end{array}$ & $\begin{array}{l}\text { Female volunteers } \\
(n=41)\end{array}$ & $\begin{array}{l}\text { Male volunteers } \\
(n=30)\end{array}$ & $\begin{array}{l}P \\
\text { value } \\
\end{array}$ \\
\hline \multicolumn{5}{|l|}{ Cross-sectional area $\left(\mathrm{mm}^{2}\right)$} \\
\hline - Ascending aorta & $515.3 \pm 186.3$ & $516.1 \pm 171.4$ & $514.0 \pm 208.3$ & 0.68 \\
\hline - Aortic arch & $376.9 \pm 148.5$ & $383.0 \pm 139.1$ & $368.2 \pm 163.7$ & 0.51 \\
\hline - Aortic isthmus & $257.9 \pm 89.5$ & $250.4 \pm 76.2$ & $268.3 \pm 105.6$ & 0.64 \\
\hline - Descending aorta above the diaphragm & $214.2 \pm 75.0$ & $213.6 \pm 68.9$ & $214.9 \pm 84.0$ & 0.81 \\
\hline \multicolumn{5}{|l|}{ Distensibility $\left(10^{-3} \mathrm{~mm} \mathrm{Hg}^{-1}\right)$} \\
\hline - Ascending aorta & $8.9 \pm 3.6$ & $9.2 \pm 3.0$ & $8.5 \pm 4.2$ & 0.11 \\
\hline - Aortic arch & $7.7 \pm 3.3$ & $8.0 \pm 3.3$ & $7.2 \pm 3.4$ & 0.2 \\
\hline - Aortic isthmus & $7.4 \pm 2.5$ & $7.7 \pm 2.3$ & $7.0 \pm 2.7$ & 0.11 \\
\hline - Descending aorta above the diaphragm & $8.3 \pm 3.0$ & $8.8 \pm 3.1$ & $7.7 \pm 2.7$ & 0.1 \\
\hline $\mathrm{PWV}(\mathrm{m} / \mathrm{s})$ & $3.6 \pm 0.7$ & $3.5 \pm 0.6$ & $3.7 \pm 0.9$ & 0.14 \\
\hline
\end{tabular}

Data are expressed as mean and standard deviation. P-values are from the Mann-Whitney- $U$ test. $P W V$, pulse wave velocity.

The latter were located at the aortic isthmus, and above the diaphragm. Distensibility was calculated [14] as:

$$
\begin{aligned}
& \text { Distensibility }\left(10^{-3} \mathrm{~mm} \mathrm{Hg}^{-1}\right) \\
& \quad=\left(\mathrm{A}_{\max }-\mathrm{A}_{\min }\right) / \mathrm{A}_{\min } \mathrm{x}\left(\mathrm{P}_{\max }-\mathrm{P}_{\min }\right), \text { where }
\end{aligned}
$$

$\mathrm{A}_{\max }$ and $\mathrm{A}_{\min }$ represent the maximal and minimal cross-sectional area of the aorta on cine CMR images, and $\mathrm{P}_{\max }$ and $\mathrm{P}_{\min }$ represent the systolic and diastolic blood pressures (in millimetres of mercury), respectively. Blood pressure was obtained non-invasively using a CMR-compatible patient monitor with sphygmomanometer (Invivo Precess ${ }^{\mathrm{TM}}$ 3160, Invivo, Orlando, USA). The sphygmomanometer cuff was placed around the right arm.

Aortic flow measurements in the ascending and proximal descending aorta with the CMR phase-contrast technique were used to assess PWV in the aortic arch.

Table 5 Correlation of cross-sectional areas with study group characteristics

\begin{tabular}{lcccc}
\hline \multirow{2}{*}{ Parameter } & \multicolumn{4}{c}{ Cross-sectional area $\left(\mathbf{m m}^{2}\right)$} \\
\cline { 2 - 5 } & $\begin{array}{c}\text { Ascending } \\
\text { aorta }\end{array}$ & $\begin{array}{c}\text { Aortic } \\
\text { arch }\end{array}$ & $\begin{array}{c}\text { Aortic } \\
\text { isthmus }\end{array}$ & $\begin{array}{c}\text { Descending aorta } \\
\text { above the diaphragm }\end{array}$ \\
\hline Age (years) & $0.80 \dagger$ & $0.80 \dagger$ & $0.81 \dagger$ & $0.87 \dagger$ \\
Height $(\mathrm{cm})$ & $0.84 \dagger$ & $0.81 \dagger$ & $0.81 \dagger$ & $0.82 \dagger$ \\
Weight $(\mathrm{kg})$ & $0.90 \dagger$ & $0.85 \dagger$ & $0.88 \dagger$ & $0.89 \dagger$ \\
$\mathrm{BSA}\left(\mathrm{m}^{2}\right)$ & $0.89 \dagger$ & $0.84 \dagger$ & $0.87 \dagger$ & $0.88 \dagger$ \\
\hline
\end{tabular}

Spearman correlation coefficients rho were calculated for the total study group; $+\mathrm{p}<0.01$.

$B S A$, body surface area.
Aortic flow versus time curves from phase-contrast cine images were obtained to determine the time delay of the distal flow curve (in the descending aorta), relative to the flow curve in the proximal ascending aorta.

The PWV was calculated by the following equation:

$$
\mathrm{PWV}=\Delta \mathrm{x} / \Delta \mathrm{t},
$$

whereas $\Delta \mathrm{x}$ is the aortic segment length (in meters) along an intra-luminal center-line between the two measurement locations, measured in a sagittally angulated view of the aortic arch, and $\Delta t$ is the time delay of the distal flow curve, relative to the proximal flow curve (in seconds, Figure 1). Furthermore mean aortic blood flow and peak systolic velocity were assessed in the ascending aorta (Table 2).

\section{Statistical analysis}

Statistical analysis was performed using MedCalc ${ }^{\circledR}$ Version 11.5.1.0. The quantitative data were expressed as mean and standard deviation. The Mann-Whitney$U$ test for independent samples was used to compare female and male subgroups. Associations between variables were examined using Spearman's rank correlation. P values below 0.05 were considered to indicate statistical significance.

Reference curves for the aortic measurements were estimated with the Lambda-Mu-Sigma (LMS)-method from Cole and Green [15,16] for each gender. This method characterizes the age dependent distribution of a target parameter based on a quantile regression fit by three different components: the median $(\mathrm{M})$, the variance $(S)$ and the skewness of the distribution, which is evaluated by an exponential factor (L) from a Box-Cox 


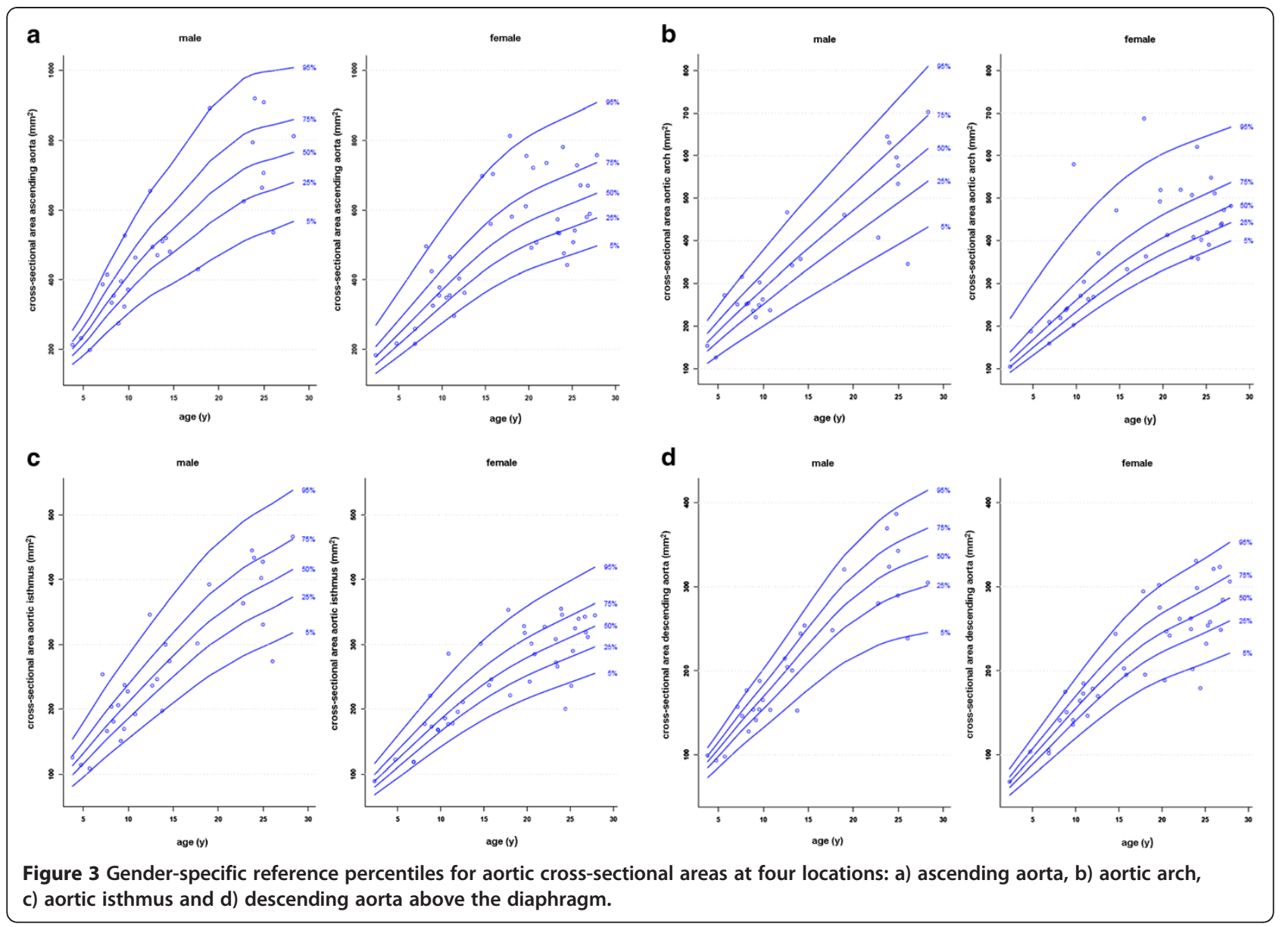

transformation. $\mathrm{L}, \mathrm{M}$ and $\mathrm{S}$ values can be used to construct reference curves by the following equation:

$$
\mathrm{C}_{\alpha}=\mathrm{M} *\left(1+\mathrm{L} * \mathrm{~S} * \mathrm{z}_{\alpha}\right)^{1 / \mathrm{L}},
$$

where $z_{\alpha}$ is the $\alpha$-quantile in the standard normal distribution, e. g. $\mathrm{z}_{0,95}=1,64$. The $\mathrm{z}$-score can be calculated from the LMS values and the measurement value for aortic cross-sectional area, diststensibility or PWV (X):

$$
\mathrm{z}-\text { score }=\left[(\mathrm{X} / \mathrm{M})^{\mathrm{L}}-1\right] /(\mathrm{L} * \mathrm{~S}) .
$$

\section{Results}

The study group characteristics are presented in Table 3. There were no significant differences between female and male subgroups.

\section{Aortic dimensions}

Table 4 shows the mean \pm SD of the aortic crosssectional areas for each position classified by gender. No significant differences were found between males and females. All cross-sectional areas correlated well with the age, height, weight, and body surface area (BSA)
(Table 5). Gender specific percentile curves between aortic cross-sectional areas and age are shown in Figure 3. Additionally, Tables 6 and 7 shows the L, M and S values relative to age and gender.

\section{Aortic distensibility and PWV}

The mean values of aortic distensibility and PWV are presented in Table 4. Figures 4 and 5 show the gender specific percentiles for aortic distensibility and PWV. In Tables 8, 9, 10 the original $\mathrm{L}, \mathrm{M}$ and $\mathrm{S}$ values for aortic distensibility and PWV are given. An age-related decrease of aortic distensibility was found for all anatomical locations $(r=-0.43$ to $-0.52, p<0.001)$. Aortic distensibility also correlated with height $(r=-0.47$ to $-0.62, \mathrm{p}<0.001)$ and body weight $(\mathrm{r}=-0.45$ to -0.59 , $\mathrm{p}<0.001)$, BSA $(\mathrm{r}=-0.47$ to $-0.61, \mathrm{p}<0.001)$. Univariate regression analysis showed a modest association between PWV and the following parameters: age, height, weight and BSA ( $\mathrm{r}=0.25$ to $0.32, \mathrm{p}=0.047$ to 0.009 ).

\section{Discussion}

This CMR study describes the quantile distribution of cross-sectional areas, distensibility and PWV of the 
Table 6 LMS parameters for aortic cross-sectional areas relative to age for girls

\begin{tabular}{|c|c|c|c|c|c|c|c|c|c|c|c|c|}
\hline \multirow[b]{2}{*}{ Age } & \multicolumn{3}{|c|}{ Ascending aorta } & \multicolumn{3}{|c|}{ Aortic arch } & \multicolumn{3}{|c|}{ Aortic isthmus } & \multicolumn{3}{|c|}{ Descending aorta above the diaphragm } \\
\hline & $\mathbf{L}$ & M & $\mathrm{s}$ & $\mathbf{L}$ & M & $S$ & $\mathbf{L}$ & $M$ & $S$ & L & M & $\mathrm{S}$ \\
\hline 0 & $-0,7876$ & 121,1903 & 0,2152 & $-2,1750$ & 73,6299 & 0,2114 & 0,1033 & 60,0696 & 0,1621 & 0,9371 & 41,0795 & 0,1398 \\
\hline 1 & $-0,7876$ & 145,9923 & 0,2140 & $-2,1750$ & 92,7307 & 0,2089 & 0,1033 & 72,6142 & 0,1617 & 0,9371 & 52,4930 & 0,1398 \\
\hline 2 & $-0,7876$ & 170,7944 & 0,2127 & $-2,1750$ & 111,8315 & 0,2064 & 0,1033 & 85,1587 & 0,1613 & 0,9371 & 63,9065 & 0,1398 \\
\hline 3 & $-0,7876$ & 195,5999 & 0,2114 & $-2,1750$ & 130,9296 & 0,2039 & 0,1033 & 97,7032 & 0,1609 & 0,9371 & 75,3185 & 0,1398 \\
\hline 4 & $-0,7876$ & 220,4539 & 0,2102 & $-2,1750$ & 149,9904 & 0,2013 & 0,1033 & 110,2465 & 0,1605 & 0,9371 & 86,7100 & 0,1398 \\
\hline 5 & $-0,7876$ & 245,4281 & 0,2089 & $-2,1750$ & 168,9588 & 0,1988 & 0,1033 & 122,7870 & 0,1601 & 0,9371 & 98,0510 & 0,1398 \\
\hline 6 & $-0,7876$ & 270,5738 & 0,2076 & $-2,1750$ & 187,8089 & 0,1963 & 0,1033 & 135,3263 & 0,1597 & 0,9371 & 109,3784 & 0,1398 \\
\hline 7 & $-0,7876$ & 295,9027 & 0,2064 & $-2,1750$ & 206,5696 & 0,1938 & 0,1033 & 147,8724 & 0,1593 & 0,9371 & 120,8531 & 0,1398 \\
\hline 8 & $-0,7876$ & 321,3290 & 0,2051 & $-2,1750$ & 225,2367 & 0,1913 & 0,1033 & 160,3915 & 0,1588 & 0,9371 & 132,5201 & 0,1398 \\
\hline 9 & $-0,7876$ & 346,5367 & 0,2038 & $-2,1750$ & 243,7024 & 0,1887 & 0,1033 & 172,7395 & 0,1584 & 0,9371 & 144,0843 & 0,1398 \\
\hline 10 & $-0,7876$ & 371,3379 & 0,2026 & $-2,1750$ & 261,8643 & 0,1862 & 0,1033 & 184,8049 & 0,1580 & 0,9371 & 155,3776 & 0,1398 \\
\hline 11 & $-0,7876$ & 395,6874 & 0,2013 & $-2,1750$ & 279,6207 & 0,1837 & 0,1033 & 196,5286 & 0,1576 & 0,9371 & 166,4608 & 0,1398 \\
\hline 12 & $-0,7876$ & 419,5583 & 0,2000 & $-2,1750$ & 296,8402 & 0,1812 & 0,1033 & 207,8452 & 0,1572 & 0,9371 & 177,3057 & 0,1398 \\
\hline 13 & $-0,7876$ & 442,8024 & 0,1988 & $-2,1750$ & 313,4236 & 0,1787 & 0,1033 & 218,7232 & 0,1568 & 0,9371 & 187,8984 & 0,1398 \\
\hline 14 & $-0,7876$ & 465,1326 & 0,1975 & $-2,1750$ & 329,2852 & 0,1761 & 0,1033 & 229,1136 & 0,1564 & 0,9371 & 198,1163 & 0,1398 \\
\hline 15 & $-0,7876$ & 486,2071 & 0,1962 & $-2,1750$ & 344,3674 & 0,1736 & 0,1033 & 238,9630 & 0,1560 & 0,9371 & 207,7776 & 0,1398 \\
\hline 16 & $-0,7876$ & 505,7398 & 0,1950 & $-2,1750$ & 358,6387 & 0,1711 & 0,1033 & 248,2461 & 0,1556 & 0,9371 & 216,7982 & 0,1398 \\
\hline 17 & $-0,7876$ & 523,5836 & 0,1937 & $-2,1750$ & 372,0983 & 0,1686 & 0,1033 & 256,9723 & 0,1552 & 0,9371 & 225,1710 & 0,1398 \\
\hline 18 & $-0,7876$ & 539,7165 & 0,1924 & $-2,1750$ & 384,7434 & 0,1661 & 0,1033 & 265,1479 & 0,1547 & 0,9371 & 232,7857 & 0,1398 \\
\hline 19 & $-0,7876$ & 554,1764 & 0,1912 & $-2,1750$ & 396,5833 & 0,1635 & 0,1033 & 272,7929 & 0,1543 & 0,9371 & 239,5830 & 0,1398 \\
\hline 20 & $-0,7876$ & 567,1207 & 0,1899 & $-2,1750$ & 407,6567 & 0,1610 & 0,1033 & 279,9469 & 0,1539 & 0,9371 & 245,6109 & 0,1398 \\
\hline 21 & $-0,7876$ & 578,7817 & 0,1886 & $-2,1750$ & 418,0442 & 0,1585 & 0,1033 & 286,6730 & 0,1535 & 0,9371 & 251,0496 & 0,1398 \\
\hline 22 & $-0,7876$ & 589,4770 & 0,1873 & $-2,1750$ & 427,8971 & 0,1560 & 0,1033 & 293,0630 & 0,1531 & 0,9371 & 256,1671 & 0,1398 \\
\hline 23 & $-0,7876$ & 599,5300 & 0,1861 & $-2,1750$ & 437,3887 & 0,1534 & 0,1033 & 299,2101 & 0,1527 & 0,9371 & 261,1406 & 0,1398 \\
\hline 24 & $-0,7876$ & 609,3164 & 0,1848 & $-2,1750$ & 446,7229 & 0,1509 & 0,1033 & 305,2232 & 0,1523 & 0,9371 & 266,1367 & 0,1398 \\
\hline 25 & $-0,7876$ & 619,1593 & 0,1835 & $-2,1750$ & 456,0570 & 0,1484 & 0,1033 & 311,2003 & 0,1518 & 0,9371 & 271,2515 & 0,1398 \\
\hline 26 & $-0,7876$ & 629,1747 & 0,1822 & $-2,1750$ & 465,4360 & 0,1459 & 0,1033 & 317,2057 & 0,1514 & 0,9371 & 276,5640 & 0,1398 \\
\hline 27 & $-0,7876$ & 639,3019 & 0,1810 & $-2,1750$ & 474,8382 & 0,1433 & 0,1033 & 323,2314 & 0,1510 & 0,9371 & 281,9813 & 0,1398 \\
\hline 28 & $-0,7876$ & 649,4860 & 0,1797 & $-2,1750$ & 484,2530 & 0,1408 & 0,1033 & 329,2650 & 0,1506 & 0,9371 & 287,4341 & 0,1398 \\
\hline 29 & $-0,7876$ & 659,6776 & 0,1784 & $-2,1750$ & 493,6694 & 0,1383 & 0,1033 & 335,2995 & 0,1502 & 0,9371 & 292,8916 & 0,1398 \\
\hline 30 & $-0,7876$ & 669,8691 & 0,1772 & $-2,1750$ & 503,0858 & 0,1358 & 0,1033 & 341,3341 & 0,1498 & 0,9371 & 298,3491 & 0,1398 \\
\hline
\end{tabular}


Table 7 LMS parameters for aortic cross-sectional areas relative to age for boys

\begin{tabular}{|c|c|c|c|c|c|c|c|c|c|c|c|c|}
\hline \multirow[b]{2}{*}{ Age } & \multicolumn{3}{|c|}{ Ascending aorta } & \multicolumn{3}{|c|}{ Aortic arch } & \multicolumn{3}{|c|}{ Aortic isthmus } & \multicolumn{3}{|c|}{ Descending aorta above the diaphragm } \\
\hline & $\mathbf{L}$ & M & $\mathrm{S}$ & $\mathbf{L}$ & M & $\mathrm{s}$ & $\mathbf{L}$ & M & $\mathrm{S}$ & $\mathbf{L}$ & $M$ & s \\
\hline 0 & 0,3091 & 91,5360 & 0,1207 & 0,8668 & 80,1737 & 0,1898 & 0,1267 & 53,0050 & 0,1987 & 1,5823 & 44,6080 & 0,1100 \\
\hline 1 & 0,3091 & 120,6960 & 0,1274 & 0,8668 & 101,7001 & 0,1897 & 0,1267 & 68,7198 & 0,1974 & 1,5823 & 57,0317 & 0,1115 \\
\hline 2 & 0,3091 & 149,8560 & 0,1341 & 0,8668 & 123,2265 & 0,1895 & 0,1267 & 84,4347 & 0,1960 & 1,5823 & 69,4554 & 0,1129 \\
\hline 3 & 0,3091 & 179,0160 & 0,1408 & 0,8668 & 144,7529 & 0,1894 & 0,1267 & 100,1495 & 0,1946 & 1,5823 & 81,8791 & 0,1143 \\
\hline 4 & 0,3091 & 208,1812 & 0,1475 & 0,8668 & 166,2791 & 0,1893 & 0,1267 & 115,8653 & 0,1932 & 1,5823 & 94,3035 & 0,1158 \\
\hline 5 & 0,3091 & 238,3791 & 0,1542 & 0,8668 & 187,7555 & 0,1891 & 0,1267 & 131,7743 & 0,1918 & 1,5823 & 106,8833 & 0,1172 \\
\hline 6 & 0,3091 & 272,8715 & 0,1604 & 0,8668 & 208,8732 & 0,1890 & 0,1267 & 148,2790 & 0,1904 & 1,5823 & 119,9057 & 0,1186 \\
\hline 7 & 0,3091 & 311,2493 & 0,1660 & 0,8668 & 229,2411 & 0,1888 & 0,1267 & 164,9648 & 0,1891 & 1,5823 & 133,0488 & 0,1201 \\
\hline 8 & 0,3091 & 346,8686 & 0,1707 & 0,8668 & 248,8676 & 0,1887 & 0,1267 & 180,7624 & 0,1877 & 1,5823 & 145,5984 & 0,1215 \\
\hline 9 & 0,3091 & 380,0230 & 0,1748 & 0,8668 & 268,0557 & 0,1886 & 0,1267 & 195,7825 & 0,1863 & 1,5823 & 157,5124 & 0,1229 \\
\hline 10 & 0,3091 & 413,8181 & 0,1782 & 0,8668 & 287,2956 & 0,1884 & 0,1267 & 210,6578 & 0,1849 & 1,5823 & 169,3366 & 0,1244 \\
\hline 11 & 0,3091 & 446,7220 & 0,1812 & 0,8668 & 306,7317 & 0,1883 & 0,1267 & 225,5414 & 0,1835 & 1,5823 & 181,3951 & 0,1258 \\
\hline 12 & 0,3091 & 476,5703 & 0,1841 & 0,8668 & 326,2205 & 0,1881 & 0,1267 & 240,3324 & 0,1822 & 1,5823 & 193,8192 & 0,1272 \\
\hline 13 & 0,3091 & 501,7973 & 0,1870 & 0,8668 & 345,4511 & 0,1880 & 0,1267 & 254,6975 & 0,1808 & 1,5823 & 206,4812 & 0,1287 \\
\hline 14 & 0,3091 & 524,0769 & 0,1902 & 0,8668 & 364,2701 & 0,1879 & 0,1267 & 268,8289 & 0,1794 & 1,5823 & 219,2939 & 0,1301 \\
\hline 15 & 0,3091 & 546,3695 & 0,1937 & 0,8668 & 382,7610 & 0,1877 & 0,1267 & 282,9653 & 0,1780 & 1,5823 & 232,0152 & 0,1316 \\
\hline 16 & 0,3091 & 569,8955 & 0,1972 & 0,8668 & 400,9805 & 0,1876 & 0,1267 & 296,9424 & 0,1766 & 1,5823 & 244,3629 & 0,1330 \\
\hline 17 & 0,3091 & 594,7536 & 0,2003 & 0,8668 & 418,9724 & 0,1875 & 0,1267 & 310,5833 & 0,1752 & 1,5823 & 256,2294 & 0,1344 \\
\hline 18 & 0,3091 & 620,9611 & 0,2025 & 0,8668 & 436,7805 & 0,1873 & 0,1267 & 323,7094 & 0,1739 & 1,5823 & 267,5155 & 0,1359 \\
\hline 19 & 0,3091 & 647,1204 & 0,2034 & 0,8668 & 454,4484 & 0,1872 & 0,1267 & 336,0814 & 0,1725 & 1,5823 & 278,0681 & 0,1373 \\
\hline 20 & 0,3091 & 670,2706 & 0,2030 & 0,8668 & 472,0177 & 0,1871 & 0,1267 & 347,4348 & 0,1711 & 1,5823 & 287,6962 & 0,1387 \\
\hline 21 & 0,3091 & 690,0681 & 0,2014 & 0,8668 & 489,5219 & 0,1869 & 0,1267 & 357,7775 & 0,1697 & 1,5823 & 296,3958 & 0,1402 \\
\hline 22 & 0,3091 & 706,8583 & 0,1990 & 0,8668 & 506,9924 & 0,1868 & 0,1267 & 367,1860 & 0,1683 & 1,5823 & 304,2102 & 0,1416 \\
\hline 23 & 0,3091 & 720,9831 & 0,1960 & 0,8668 & 524,4603 & 0,1866 & 0,1267 & 375,7366 & 0,1670 & 1,5823 & 311,1823 & 0,1430 \\
\hline 24 & 0,3091 & 732,2902 & 0,1926 & 0,8668 & 541,9124 & 0,1865 & 0,1267 & 383,4824 & 0,1656 & 1,5823 & 317,3075 & 0,1445 \\
\hline 25 & 0,3091 & 740,4053 & 0,1889 & 0,8668 & 559,3076 & 0,1864 & 0,1267 & 390,6086 & 0,1642 & 1,5823 & 322,5658 & 0,1459 \\
\hline 26 & 0,3091 & 747,1815 & 0,1849 & 0,8668 & 576,7470 & 0,1862 & 0,1267 & 397,7409 & 0,1628 & 1,5823 & 327,1568 & 0,1473 \\
\hline 27 & 0,3091 & 754,8518 & 0,1805 & 0,8668 & 594,3196 & 0,1861 & 0,1267 & 405,3735 & 0,1614 & 1,5823 & 331,4000 & 0,1488 \\
\hline 28 & 0,3091 & 763,4054 & 0,1758 & 0,8668 & 611,9863 & 0,1860 & 0,1267 & 413,3799 & 0,1601 & 1,5823 & 335,4719 & 0,1502 \\
\hline 29 & 0,3091 & 772,1960 & 0,1711 & 0,8668 & 629,6783 & 0,1858 & 0,1267 & 421,4867 & 0,1587 & 1,5823 & 339,4979 & 0,1516 \\
\hline 30 & 0,3091 & 780,9891 & 0,1663 & 0,8668 & 647,3706 & 0,1857 & 0,1267 & 429,5945 & 0,1573 & 1,5823 & 343,5234 & 0,1531 \\
\hline
\end{tabular}




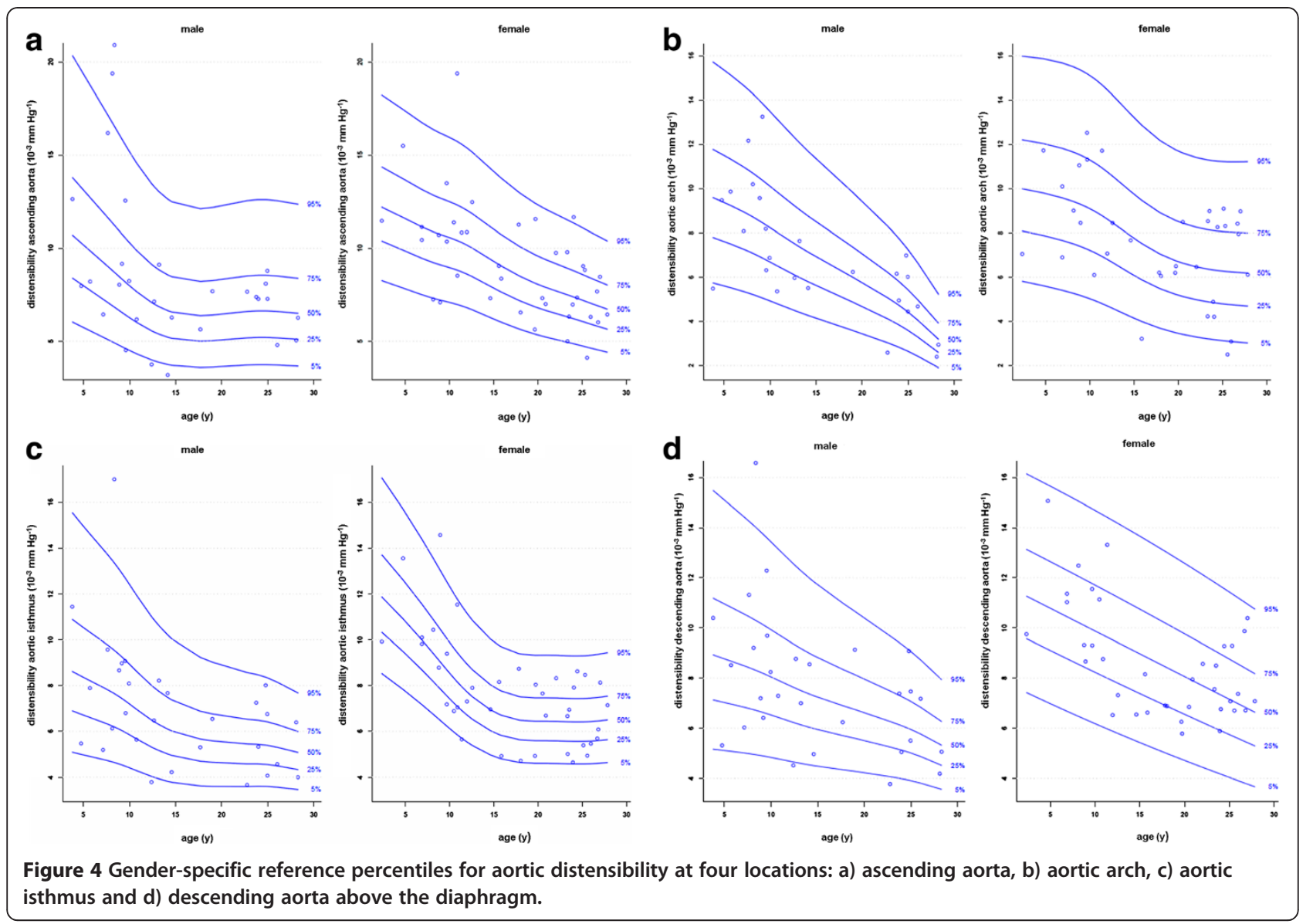

thoracic aorta in heart-healthy children and young adults between their $3^{\text {rd }}$ and $29^{\text {th }}$ year of life. Defining the normal range for aortic size and bio-elastic properties is an important aid in the early detection of adverse aortic changes.

\section{Aortic dimensions}

Knowledge of the size of the thoracic aorta is important for the treatment of patients with congenital and acquired cardiovascular diseases. CMR allows an exact assessment of the aortic anatomy, independent of acoustic windows, and is therefore an optimal tool to detect anatomic abnormalities of the aorta such as dilatation or aneurysm formation [17]. We provide normal data for aortic cross-sectional areas in the form of percentile curves by age and gender. Normal data for aortic dimensions in children have been reported in various echocardiographic [18], angiocardiographic $[19,20]$ and CMR studies $[21,22]$.

The CMR study from Kaiser et al. [20] reported aortic diameters measured by contrast-enhanced (CE) CMR angiography in 53 children. This method was limited by the fact that CE-CMR images are static and represent a summation of all cardiac phases which may affect a comparison to ECG-gated acquisitions such as in echocardiography or in our study. Furthermore, they measured aortic diameters instead of cross-sectional areas.

Another early CMR-study from Mohiaddin et al. [22] assessed aortic cross-sectional areas from enddiastolic spin echo images in 70 predominantly adult volunteers between the ages of 10 and 83 years. We confirmed their finding that aortic dimensions are positively correlated with age, but our study also covers children younger than 10 years, an age range where aortic dimensions and cardiac structures change rapidly according to somatic growth in prepubertal children [23]. Normal data for aortic cross-sectional areas have been reported by Rammos et al using angiocardiography [19]. As in our study, they showed a good correlation between BSA and aortic cross-sectional areas. However, their reported data are smaller than in our study, which may be mainly caused by the different technique.

However, the data from the mentioned studies are not exactly comparable to our measurements. Most studies used different imaging modalities [18-20]. Furthermore, they report aortic diameters, or measured them in order to calculate cross-sectional areas [18]. CMR allows a direct measurement of aortic cross-sectional areas which 

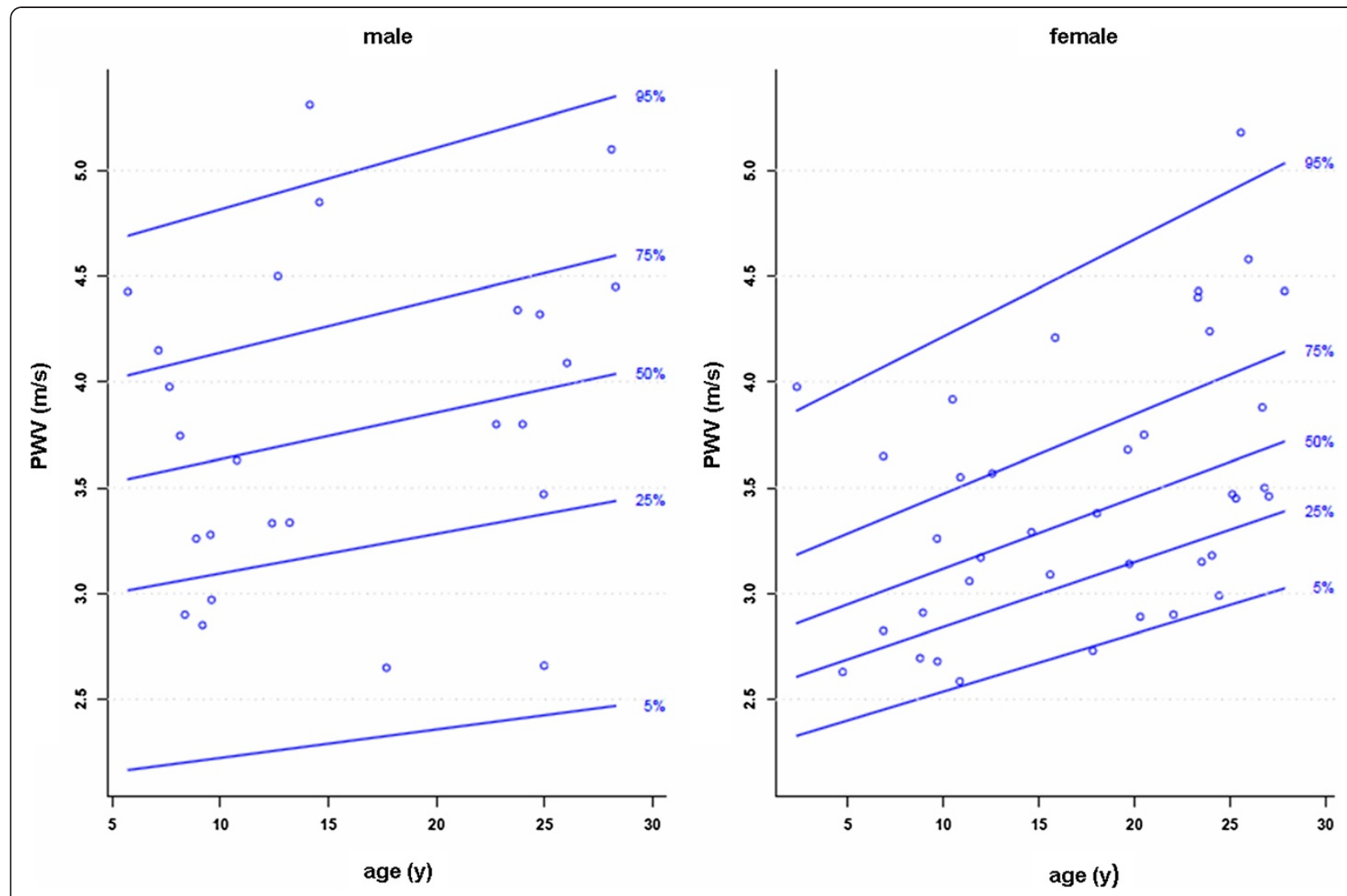

Figure 5 Gender-specific reference percentiles for PWV in the aortic arch.

is a more accurate approach to assess aortic size, since vessels are not circular in all segments and show an inter-individual anatomic variability.

The observed quantile distributions for aortic dimensions are of clinical value to detect pathologic anatomical changes of the aorta in children and young adults and will serve as reference values for future CMR research studies.

\section{Aortic distensibility and PWV}

This is the first study to provide reference CMR values for aortic distensibility and PWV in children and young adults, in conjunction with measurements of aortic size. The percentile ranges show that aortic distensibility decreases with age, whereas PWV increases with age. Age-associated changes and reference values of aortic distensibility and PWV in children and adults have also been reported in studies using different techniques. Senzaki et al. examined 112 patients with an age range from 6 months to 20 years by cardiac catherization. They showed that the arterial compliance normalized to body surface area significantly decreased with age [24]. The study by Avioli et al. used transcutaneous Doppler techniques to assess aortic PWV in subjects with an age range from 3 to 89 years. In their study aortic PWV significantly increased with age [25]. Another study measured PWV with ultrasound methods in 206 patients aged 0-15 years. Their median PWV was $3.04 \mathrm{~m} / \mathrm{s}$ which is comparable to our data. However, in contrast to our study PWV was independent of age, which may be caused by the young age of their study group [26]. CMR assessment of aortic PWV showed good agreement with PWV obtained from invasive pressure measurements as the gold standard [27]. Unlike in ultrasound CMR is not limited to acoustic windows and does not only provide an estimation of aortic PWV [1,27].

The aorta acts as a conduit delivering blood to the peripheral organs and transforms the pulsatile effect caused by ventricular ejection into a continuous blood flow [1]. As shown aortic distensibility decreases and PWV increases during age. The decreasing aortic elasticity observed in our young cohort may be related to normal structural wall changes during aging [28]. An increase in intimal-medial thickness after birth has been demonstrated in an earlier study [28]. The aortic elastic properties depend largely on the presence of elastic 
Table 8 LMS parameters for aortic distensibility relative to age for girls

\begin{tabular}{|c|c|c|c|c|c|c|c|c|c|c|c|c|}
\hline \multirow[b]{2}{*}{ Age } & \multicolumn{3}{|c|}{ Ascending aorta } & \multicolumn{3}{|c|}{ Aortic arch } & \multicolumn{3}{|c|}{ Aortic isthmus } & \multicolumn{3}{|c|}{ Descending aorta above the diaphragm } \\
\hline & L & $M$ & $S$ & $\mathbf{L}$ & $M$ & $S$ & $\mathbf{L}$ & $M$ & $\mathrm{~S}$ & $\mathbf{L}$ & $M$ & $\mathrm{~S}$ \\
\hline 0 & $-0,0721$ & 12,7303 & 0,2388 & 0,2825 & 10,1659 & 0,2971 & $-0,2728$ & 12,7827 & 0,2097 & 0,3847 & 11,6928 & 0,2263 \\
\hline 1 & $-0,0721$ & 12,5028 & 0,2396 & 0,2825 & 10,0908 & 0,3006 & $-0,2728$ & 12,3919 & 0,2100 & 0,3847 & 11,5113 & 0,2297 \\
\hline 2 & $-0,0721$ & 12,2753 & 0,2403 & 0,2825 & 10,0157 & 0,3041 & $-0,2728$ & 12,0010 & 0,2102 & 0,3847 & 11,3298 & 0,2331 \\
\hline 3 & $-0,0721$ & 12,0477 & 0,2411 & 0,2825 & 9,9404 & 0,3076 & $-0,2728$ & 11,6098 & 0,2104 & 0,3847 & 11,1483 & 0,2366 \\
\hline 4 & $-0,0721$ & 11,8176 & 0,2419 & 0,2825 & 9,8619 & 0,3110 & $-0,2728$ & 11,2134 & 0,2106 & 0,3847 & 10,9668 & 0,2400 \\
\hline 5 & $-0,0721$ & 11,5817 & 0,2427 & 0,2825 & 9,7752 & 0,3145 & $-0,2728$ & 10,8041 & 0,2108 & 0,3847 & 10,7853 & 0,2434 \\
\hline 6 & $-0,0721$ & 11,3421 & 0,2435 & 0,2825 & 9,6765 & 0,3180 & $-0,2728$ & 10,3772 & 0,2110 & 0,3847 & 10,6038 & 0,2469 \\
\hline 7 & $-0,0721$ & 11,1121 & 0,2443 & 0,2825 & 9,5629 & 0,3215 & $-0,2728$ & 9,9344 & 0,2112 & 0,3847 & 10,4223 & 0,2503 \\
\hline 8 & $-0,0721$ & 10,9051 & 0,2451 & 0,2825 & 9,4311 & 0,3250 & $-0,2728$ & 9,4780 & 0,2114 & 0,3847 & 10,2408 & 0,2537 \\
\hline 9 & $-0,0721$ & 10,7290 & 0,2459 & 0,2825 & 9,2748 & 0,3285 & $-0,2728$ & 9,0114 & 0,2117 & 0,3847 & 10,0593 & 0,2572 \\
\hline 10 & $-0,0721$ & 10,5679 & 0,2467 & 0,2825 & 9,0871 & 0,3320 & $-0,2728$ & 8,5463 & 0,2119 & 0,3847 & 9,8778 & 0,2606 \\
\hline 11 & $-0,0721$ & 10,3851 & 0,2474 & 0,2825 & 8,8635 & 0,3354 & $-0,2728$ & 8,1077 & 0,2121 & 0,3847 & 9,6963 & 0,2640 \\
\hline 12 & $-0,0721$ & 10,1582 & 0,2482 & 0,2825 & 8,6056 & 0,3389 & $-0,2728$ & 7,7159 & 0,2123 & 0,3847 & 9,5149 & 0,2675 \\
\hline 13 & $-0,0721$ & 9,8884 & 0,2490 & 0,2825 & 8,3257 & 0,3424 & $-0,2728$ & 7,3784 & 0,2125 & 0,3847 & 9,3334 & 0,2709 \\
\hline 14 & $-0,0721$ & 9,5911 & 0,2498 & 0,2825 & 8,0371 & 0,3459 & $-0,2728$ & 7,0939 & 0,2127 & 0,3847 & 9,1519 & 0,2743 \\
\hline 15 & $-0,0721$ & 9,2905 & 0,2506 & 0,2825 & 7,7528 & 0,3494 & $-0,2728$ & 6,8625 & 0,2129 & 0,3847 & 8,9705 & 0,2777 \\
\hline 16 & $-0,0721$ & 9,0033 & 0,2514 & 0,2825 & 7,4850 & 0,3529 & $-0,2728$ & 6,6852 & 0,2131 & 0,3847 & 8,7890 & 0,2812 \\
\hline 17 & $-0,0721$ & 8,7345 & 0,2522 & 0,2825 & 7,2434 & 0,3563 & $-0,2728$ & 6,5631 & 0,2134 & 0,3847 & 8,6076 & 0,2846 \\
\hline 18 & $-0,0721$ & 8,4850 & 0,2529 & 0,2825 & 7,0315 & 0,3598 & $-0,2728$ & 6,4885 & 0,2136 & 0,3847 & 8,4262 & 0,2880 \\
\hline 19 & $-0,0721$ & 8,2574 & 0,2537 & 0,2825 & 6,8508 & 0,3633 & $-0,2728$ & 6,4533 & 0,2138 & 0,3847 & 8,2448 & 0,2915 \\
\hline 20 & $-0,0721$ & 8,0546 & 0,2545 & 0,2825 & 6,6995 & 0,3668 & $-0,2728$ & 6,4449 & 0,2140 & 0,3847 & 8,0635 & 0,2949 \\
\hline 21 & $-0,0721$ & 7,8749 & 0,2553 & 0,2825 & 6,5740 & 0,3703 & $-0,2728$ & 6,4447 & 0,2142 & 0,3847 & 7,8822 & 0,2983 \\
\hline 22 & $-0,0721$ & 7,7106 & 0,2561 & 0,2825 & 6,4710 & 0,3738 & $-0,2728$ & 6,4391 & 0,2144 & 0,3847 & 7,7008 & 0,3017 \\
\hline 23 & $-0,0721$ & 7,5479 & 0,2569 & 0,2825 & 6,3882 & 0,3772 & $-0,2728$ & 6,4264 & 0,2146 & 0,3847 & 7,5195 & 0,3052 \\
\hline 24 & $-0,0721$ & 7,3842 & 0,2577 & 0,2825 & 6,3235 & 0,3807 & $-0,2728$ & 6,4171 & 0,2148 & 0,3847 & 7,3382 & 0,3086 \\
\hline 25 & $-0,0721$ & 7,2113 & 0,2584 & 0,2825 & 6,2744 & 0,3842 & $-0,2728$ & 6,4170 & 0,2150 & 0,3847 & 7,1570 & 0,3120 \\
\hline 26 & $-0,0721$ & 7,0343 & 0,2592 & 0,2825 & 6,2371 & 0,3877 & $-0,2728$ & 6,4317 & 0,2152 & 0,3847 & 6,9757 & 0,3155 \\
\hline 27 & $-0,0721$ & 6,8647 & 0,2600 & 0,2825 & 6,2084 & 0,3912 & $-0,2728$ & 6,4666 & 0,2154 & 0,3847 & 6,7944 & 0,3189 \\
\hline 28 & $-0,0721$ & 6,6951 & 0,2608 & 0,2825 & 6,1806 & 0,3947 & $-0,2728$ & 6,5104 & 0,2156 & 0,3847 & 6,6132 & 0,3223 \\
\hline 29 & $-0,0721$ & 6,5250 & 0,2616 & 0,2825 & 6,1527 & 0,3981 & $-0,2728$ & 6,5550 & 0,2158 & 0,3847 & 6,4319 & 0,3257 \\
\hline 30 & $-0,0721$ & 6,3550 & 0,2624 & 0,2825 & 6,1249 & 0,4016 & $-0,2728$ & 6,5997 & 0,2160 & 0,3847 & 6,2506 & 0,3292 \\
\hline
\end{tabular}


Table 9 LMS parameters for aortic distensibility relative to age for boys

\begin{tabular}{|c|c|c|c|c|c|c|c|c|c|c|c|c|}
\hline \multirow[b]{2}{*}{ Age } & \multicolumn{3}{|c|}{ Ascending aorta } & \multicolumn{3}{|c|}{ Aortic arch } & \multicolumn{3}{|c|}{ Aortic isthmus } & \multicolumn{3}{|c|}{ Descending aorta above the diaphragm } \\
\hline & $\mathrm{L}$ & M & $\mathrm{S}$ & $\mathbf{L}$ & M & $S$ & $\mathbf{L}$ & M & $S$ & $\mathbf{L}$ & M & $\mathrm{S}$ \\
\hline 0 & $-0,1879$ & 12,3602 & 0,3680 & 0,0801 & 10,2881 & 0,3061 & $-0,2022$ & 9,4472 & 0,3533 & $-0,0079$ & 9,4241 & 0,3478 \\
\hline 1 & $-0,1879$ & 11,9220 & 0,3680 & 0,0801 & 10,1050 & 0,3061 & $-0,2022$ & 9,2308 & 0,3494 & $-0,0079$ & 9,2938 & 0,3441 \\
\hline 2 & $-0,1879$ & 11,4838 & 0,3680 & 0,0801 & 9,9218 & 0,3061 & $-0,2022$ & 9,0144 & 0,3454 & $-0,0079$ & 9,1635 & 0,3404 \\
\hline 3 & $-0,1879$ & 11,0456 & 0,3680 & 0,0801 & 9,7386 & 0,3061 & $-0,2022$ & 8,7980 & 0,3415 & $-0,0079$ & 9,0331 & 0,3367 \\
\hline 4 & $-0,1879$ & 10,6075 & 0,3680 & 0,0801 & 9,5554 & 0,3061 & $-0,2022$ & 8,5816 & 0,3375 & $-0,0079$ & 8,9028 & 0,3330 \\
\hline 5 & $-0,1879$ & 10,1700 & 0,3680 & 0,0801 & 9,3705 & 0,3061 & $-0,2022$ & 8,3685 & 0,3335 & $-0,0079$ & 8,7730 & 0,3293 \\
\hline 6 & $-0,1879$ & 9,7343 & 0,3680 & 0,0801 & 9,1780 & 0,3061 & $-0,2022$ & 8,1629 & 0,3296 & $-0,0079$ & 8,6433 & 0,3256 \\
\hline 7 & $-0,1879$ & 9,2990 & 0,3680 & 0,0801 & 8,9719 & 0,3061 & $-0,2022$ & 7,9576 & 0,3256 & $-0,0079$ & 8,5103 & 0,3219 \\
\hline 8 & $-0,1879$ & 8,8602 & 0,3680 & 0,0801 & 8,7467 & 0,3061 & $-0,2022$ & 7,7410 & 0,3216 & $-0,0079$ & 8,3694 & 0,3182 \\
\hline 9 & $-0,1879$ & 8,4151 & 0,3680 & 0,0801 & 8,4980 & 0,3061 & $-0,2022$ & 7,4918 & 0,3177 & $-0,0079$ & 8,2157 & 0,3145 \\
\hline 10 & $-0,1879$ & 7,9776 & 0,3680 & 0,0801 & 8,2310 & 0,3061 & $-0,2022$ & 7,2033 & 0,3137 & $-0,0079$ & 8,0497 & 0,3108 \\
\hline 11 & $-0,1879$ & 7,5683 & 0,3680 & 0,0801 & 7,9577 & 0,3061 & $-0,2022$ & 6,8970 & 0,3098 & $-0,0079$ & 7,8764 & 0,3071 \\
\hline 12 & $-0,1879$ & 7,2051 & 0,3680 & 0,0801 & 7,6865 & 0,3061 & $-0,2022$ & 6,6042 & 0,3058 & $-0,0079$ & 7,7035 & 0,3034 \\
\hline 13 & $-0,1879$ & 6,9030 & 0,3680 & 0,0801 & 7,4220 & 0,3061 & $-0,2022$ & 6,3480 & 0,3018 & $-0,0079$ & 7,5379 & 0,2997 \\
\hline 14 & $-0,1879$ & 6,6697 & 0,3680 & 0,0801 & 7,1669 & 0,3061 & $-0,2022$ & 6,1310 & 0,2979 & $-0,0079$ & 7,3831 & 0,2959 \\
\hline 15 & $-0,1879$ & 6,5089 & 0,3680 & 0,0801 & 6,9220 & 0,3061 & $-0,2022$ & 5,9529 & 0,2939 & $-0,0079$ & 7,2400 & 0,2922 \\
\hline 16 & $-0,1879$ & 6,4138 & 0,3680 & 0,0801 & 6,6851 & 0,3061 & $-0,2022$ & 5,8175 & 0,2899 & $-0,0079$ & 7,1082 & 0,2885 \\
\hline 17 & $-0,1879$ & 6,3729 & 0,3680 & 0,0801 & 6,4532 & 0,3061 & $-0,2022$ & 5,7175 & 0,2860 & $-0,0079$ & 6,9844 & 0,2848 \\
\hline 18 & $-0,1879$ & 6,3745 & 0,3680 & 0,0801 & 6,2234 & 0,3061 & $-0,2022$ & 5,6445 & 0,2820 & $-0,0079$ & 6,8653 & 0,2811 \\
\hline 19 & $-0,1879$ & 6,4062 & 0,3680 & 0,0801 & 5,9926 & 0,3061 & $-0,2022$ & 5,5886 & 0,2781 & $-0,0079$ & 6,7467 & 0,2774 \\
\hline 20 & $-0,1879$ & 6,4551 & 0,3680 & 0,0801 & 5,7579 & 0,3061 & $-0,2022$ & 5,5400 & 0,2741 & $-0,0079$ & 6,6246 & 0,2737 \\
\hline 21 & $-0,1879$ & 6,5111 & 0,3680 & 0,0801 & 5,5167 & 0,3061 & $-0,2022$ & 5,4988 & 0,2701 & $-0,0079$ & 6,4987 & 0,2700 \\
\hline 22 & $-0,1879$ & 6,5646 & 0,3680 & 0,0801 & 5,2667 & 0,3061 & $-0,2022$ & 5,4678 & 0,2662 & $-0,0079$ & 6,3697 & 0,2663 \\
\hline 23 & $-0,1879$ & 6,6062 & 0,3680 & 0,0801 & 5,0054 & 0,3061 & $-0,2022$ & 5,4496 & 0,2622 & $-0,0079$ & 6,2384 & 0,2626 \\
\hline 24 & $-0,1879$ & 6,6277 & 0,3680 & 0,0801 & 4,7261 & 0,3061 & $-0,2022$ & 5,4328 & 0,2583 & $-0,0079$ & 6,1017 & 0,2589 \\
\hline 25 & $-0,1879$ & 6,6242 & 0,3680 & 0,0801 & 4,4155 & 0,3061 & $-0,2022$ & 5,3874 & 0,2543 & $-0,0079$ & 5,9498 & 0,2552 \\
\hline 26 & $-0,1879$ & 6,5975 & 0,3680 & 0,0801 & 4,0684 & 0,3061 & $-0,2022$ & 5,3095 & 0,2503 & $-0,0079$ & 5,7759 & 0,2515 \\
\hline 27 & $-0,1879$ & 6,5577 & 0,3680 & 0,0801 & 3,6929 & 0,3061 & $-0,2022$ & 5,2154 & 0,2464 & $-0,0079$ & 5,5826 & 0,2478 \\
\hline 28 & $-0,1879$ & 6,5116 & 0,3680 & 0,0801 & 3,3021 & 0,3061 & $-0,2022$ & 5,1114 & 0,2424 & $-0,0079$ & 5,3785 & 0,2441 \\
\hline 29 & $-0,1879$ & 6,4643 & 0,3680 & 0,0801 & 2,9079 & 0,3061 & $-0,2022$ & 5,0026 & 0,2384 & $-0,0079$ & 5,1722 & 0,2404 \\
\hline 30 & $-0,1879$ & 6,4170 & 0,3680 & 0,0801 & 2,5137 & 0,3061 & $-0,2022$ & 4,8936 & 0,2345 & $-0,0079$ & 4,9658 & 0,2367 \\
\hline
\end{tabular}


Table 10 LMS parameters for PWV relative to age and gender

\begin{tabular}{|c|c|c|c|c|c|c|}
\hline \multirow[b]{2}{*}{ Age } & \multicolumn{3}{|c|}{ Male } & \multicolumn{3}{|c|}{ Female } \\
\hline & L & $M$ & $S$ & L & $M$ & $S$ \\
\hline 0 & 1,4844 & 3,4147 & 0,2122 & $-1,5196$ & 2,7808 & 0,1468 \\
\hline 1 & 1,4844 & 3,4367 & 0,2122 & $-1,5196$ & 2,8144 & 0,1469 \\
\hline 2 & 1,4844 & 3,4587 & 0,2122 & $-1,5196$ & 2,8481 & 0,1469 \\
\hline 3 & 1,4844 & 3,4808 & 0,2122 & $-1,5196$ & 2,8817 & 0,1469 \\
\hline 4 & 1,4844 & 3,5028 & 0,2122 & $-1,5196$ & 2,9154 & 0,1470 \\
\hline 5 & 1,4844 & 3,5248 & 0,2122 & $-1,5196$ & 2,9490 & 0,1470 \\
\hline 6 & 1,4844 & 3,5469 & 0,2122 & $-1,5196$ & 2,9827 & 0,1470 \\
\hline 7 & 1,4844 & 3,5689 & 0,2122 & $-1,5196$ & 3,0163 & 0,1470 \\
\hline 8 & 1,4844 & 3,5909 & 0,2122 & $-1,5196$ & 3,0499 & 0,1471 \\
\hline 9 & 1,4844 & 3,6129 & 0,2122 & $-1,5196$ & 3,0836 & 0,1471 \\
\hline 10 & 1,4844 & 3,6350 & 0,2122 & $-1,5196$ & 3,1172 & 0,1471 \\
\hline 11 & 1,4844 & 3,6570 & 0,2122 & $-1,5196$ & 3,1509 & 0,1471 \\
\hline 12 & 1,4844 & 3,6790 & 0,2122 & $-1,5196$ & 3,1845 & 0,1472 \\
\hline 13 & 1,4844 & 3,7011 & 0,2122 & $-1,5196$ & 3,2182 & 0,1472 \\
\hline 14 & 1,4844 & 3,7231 & 0,2122 & $-1,5196$ & 3,2518 & 0,1472 \\
\hline 15 & 1,4844 & 3,7451 & 0,2122 & $-1,5196$ & 3,2855 & 0,1473 \\
\hline 16 & 1,4844 & 3,7672 & 0,2122 & $-1,5196$ & 3,3192 & 0,1473 \\
\hline 17 & 1,4844 & 3,7892 & 0,2122 & $-1,5196$ & 3,3528 & 0,1473 \\
\hline 18 & 1,4844 & 3,8112 & 0,2122 & $-1,5196$ & 3,3865 & 0,1473 \\
\hline 19 & 1,4844 & 3,8333 & 0,2122 & $-1,5196$ & 3,4201 & 0,1474 \\
\hline 20 & 1,4844 & 3,8553 & 0,2122 & $-1,5196$ & 3,4538 & 0,1474 \\
\hline 21 & 1,4844 & 3,8773 & 0,2122 & $-1,5196$ & 3,4875 & 0,1474 \\
\hline 22 & 1,4844 & 3,8994 & 0,2122 & $-1,5196$ & 3,5211 & 0,1475 \\
\hline 23 & 1,4844 & 3,9214 & 0,2122 & $-1,5196$ & 3,5548 & 0,1475 \\
\hline 24 & 1,4844 & 3,9434 & 0,2122 & $-1,5196$ & 3,5885 & 0,1475 \\
\hline 25 & 1,4844 & 3,9655 & 0,2122 & $-1,5196$ & 3,6221 & 0,1476 \\
\hline 26 & 1,4844 & 3,9875 & 0,2122 & $-1,5196$ & 3,6558 & 0,1476 \\
\hline 27 & 1,4844 & 4,0096 & 0,2122 & $-1,5196$ & 3,6895 & 0,1476 \\
\hline 28 & 1,4844 & 4,0316 & 0,2122 & $-1,5196$ & 3,7231 & 0,1476 \\
\hline 29 & 1,4844 & 4,0536 & 0,2122 & $-1,5196$ & 3,7568 & 0,1477 \\
\hline 30 & 1,4844 & 4,0757 & 0,2122 & $-1,5196$ & 3,7905 & 0,1477 \\
\hline
\end{tabular}

$L M S, L=$ skewness of the distribution, $M=$ median, and $S=$ variance.

fibres in the vessel wall, which have a maximum rate in the perinatal period followed by a fast decrease already during childhood [29]. Besides these developmental changes aortic wall mechanics and stress seems to play an important role in aortic stiffening. In the course of a lifetime the human aorta will undergo billions of cycles of expansion and contractions. This cyclic mechanical stress leads to fragmentation of elastic fibres and causes a transfer of stress to the stiffer collagen fibres. The loss of elastin results in a reduction of aortic elasticity [30]. In adults, decreased aortic elasticity has adverse effects on cardiac systolic and diastolic function, due to increased left ventricular afterload and myocardial oxygen consumption as well as impaired coronary perfusion [31].

Our data may be of interest in various diseases and pathological conditions that can affect aortic bioelasticity already in children and young adults. Impaired aortic bioelasticity has been reported for instance in patients with Marfan syndrome [14], tetralogy of Fallot [5], Turner's syndrome [32] and aortic coarctation [4]. In a recently published study we could show that patients with hypoplastic left heart syndrome have severly reduced aortic distensibility [3]. Furthermore, some functional vascular parameters are impaired in obese children [33]. Considering the increasing use of CMR for non-invasive scientific and clinical studies, the presented data may help in evaluating aortic bioelastic function and cardiovascular risk stratification with these diseases.

\section{Limitations}

As it is difficult to recruit healthy children as volunteers for a CMR study, the sample size of our cohort is small in comparison to echocardiographic studies but fulfills the demand for statistical evaluation.

\section{Conclusions}

We provide percentiles for aortic cross-sectional areas, aortic distensibilty and PWV for children at various ages. They can be of clinical value in patients with various cardiac and vascular diseases and may serve as reference values for further CMR research studies.

\section{Competing interests}

The authors declare that they have no competing interests.

\section{Authors' contributions}

IV and CR developed the concept and design of the study, collected the data and analyzed the results. They also drafted the manuscript and had the primary responsibility for the final content. JH from the Department for Medical Informatics and Statistics participated substantially in statistical analysis and data interpretation. EP and $\mathrm{CH}$ assisted substantially in data acquisition and analysis. DDG, JHH and CP revised the article for important intellectual content. $\mathrm{HHK}$ and $\mathrm{MJH}$ participated mainly in the design of the study and the critical revision of the manuscript. All authors have read and approved the final manuscript.

\section{Acknowledgements}

We thank the Fördergemeinschaft Deutsche Kinderherzzentren e.V. (Friedrich-Wilhelm-Straße 45, 53113 Bonn, www.kinderherzen.de) for their financial support.

\section{Author details}

'Department of Congenital Heart Disease and Pediatric Cardiology, University Hospital of Schleswig-Holstein, Campus Kiel, Arnold-Heller-Str. 3, 24105, Kiel, Germany. 'Department for Medical Informatics and Statistics, University Hospital of Schleswig-Holstein, Campus Kiel, Arnold-Heller-Str. 3, 24105, Kiel, Germany. ${ }^{3}$ Department of Radiology, Brigham \& Women's Hospital, Harvard University, 75 Francis Street, Boston, MA 02115, USA.

Received: 9 November 2011 Accepted: 16 October 2012

Published: 14 November 2012 


\section{References}

1. Metafratzi ZM, Efremidis SC, Skopelitou AS, De Roos A. The clinical significance of aortic compliance and its assessment with magnetic resonance imaging. J Cardiovasc Magn Reson. 2002; 4:481-91.

2. London GM, Guerin AP. Influence of arterial pulse and reflected waves on blood pressure and cardiac function. Am Heart J. 1999; 138:220-4

3. Voges I, Jerosch-Herold M, Hedderich J, Westphal C, Hart C, Helle M, Scheewe J, Pardun E, Kramer HH, Rickers C. Maladaptive aortic properties in children after palliation of hypoplastic left heart syndrome assessed by cardiovascular magnetic resonance imaging. Circulation. 2010; 122:1068-76.

4. Kühn A, Baumgartner D, Baumgartner C, Hörer J, Schreiber C, Hess J, Vogt M. Impaired elastic properties of the ascending aorta persist within the first 3 years after neonatal coarctation repair. Pediatr Cardiol. 2009; 30:46-51.

5. Grotenhuis HB, Ottenkamp J, de Bruijn L, Westenberg JJ, Vliegen HW, Kroft LJ, de Roos A. Aortic elasticity and size are associated with aortic regurgitation and left ventricular dysfunction in tetralogy of Fallot after pulmonary valve replacement. Heart. 2009; 95:1931-6.

6. Grotenhuis HB, Ottenkamp J, Fontein D, Vliegen HW, Westenberg JJ, Kroft LJ, de Roos A. Aortic elasticity and left ventricular function after arterial switch operation: MR imaging-initial experience. Radiology. 2008; 249:801-9.

7. Aboulhosn J, Child JS. Left ventricular outflow obstruction: subaortic stenosis, bicuspid aortic valve, supravalvar aortic stenosis, and coarctation of the aorta. Circulation. 2006; 114:2412-22.

8. Laurent S, Katsahian S, Fassot C, Tropeano Al, Gautier I, Laloux B, Boutouyrie P. Aortic stiffness is an independent predictor of fatal stroke in essential hypertension. Stroke. 2003; 34:1203-6.

9. Boese JM, Bock M, Schoenberg SO, Schad LR. Estimation of aortic compliance using magnetic resonance pulse wave velocity measurement. Phys Med Biol. 2000; 45:1703-13.

10. Mitchell GF, Hwang SJ, Vasan RS, Larson MG, Pencina MJ, Hamburg NM, Vita JA, Levy D, Benjamin EJ. Arterial stiffness and cardiovascular events: the Framingham heart study. Circulation. 2010; 121:505-11.

11. Laurent S, Cockcroft J, Van Bortel L, Boutouyrie P, Giannattasio C, Hayoz D, Pannier B, Vlachopoulos C, Wilkinson I, Struijker-Boudier H. European network for Non-invasive investigation of large arteries: expert consensus document on arterial stiffness: methodological issues and clinical applications. Eur Heart J. 2006; 27:2588-605.

12. Mohiaddin RH, Underwood SR, Bogren HG, Firmin DN, Klipstein RH, Rees RS, Longmore DB. Regional aortic compliance studied by magnetic resonance imaging: the effects of age, training, and coronary artery disease. Br Heart J. 1989; 62:90-6.

13. Mohiaddin RH, Firmin DN, Longmore DB. Age-related changes of human aortic flow wave velocity measured noninvasively by magnetic resonance imaging. J App/ Physiol. 1993; 74:492-7.

14. Groenink M, de Roos A, Mulder BJ, Spaan JA, van der Wall EE. Changes in aortic distensibility and pulse wave velocity assessed with magnetic resonance imaging following beta-blocker therapy in the Marfan syndrome. Am J Cardiol. 1998; 82:203-8.

15. Cole TJ, Green PJ. Smoothing reference centile curves: the LMS method and penalized likelihood. Stat Med. 1992; 11:1305-19.

16. Cole TJ. The LMS method for constructing normalized growth standards. Eur J Clin Nutr. 1990; 44:45-60.

17. Pennell DJ, Sechtem UP, Higgins CB, Manning WJ, Pohost GM, Rademakers FE, van Rossum AC, Shaw $\sqcup$, Yucel EK. European Society of cardiology; Society for Cardiovascular Magnetic Resonance: Clinical indications for cardiovascular magnetic resonance (CMR): Consensus Panel report. J Cardiovasc Magn Reson. 2004; 6:727-65

18. Snider AR, Enderlein MA, Teitel DF, Juster RP. Two-dimensional echocardiographic determination of aortic and pulmonary artery sizes from infancy to adulthood in normal subjects. Am J Cardiol. 1984; 53:218-24.

19. Rammos S, Apostolopoulou SC, Kramer HH, Kozlik-Feldmann R, Heusch A, Laskari CV, Anagnostopoulos C. Normative angiographic data relating to the dimensions of the aorta and pulmonary trunk in children and adolescents. Cardiol Young. 2005; 15:119-24.

20. Clarkson PM, Brandt PW. Aortic diameters in infants and young children: normative angiographic data. Pediatr Cardiol. 1985; 6:3-6.

21. Kaiser T, Kellenberger $C J$, Albisetti M, Bergsträsser E, Valsangiacomo Buechel ER. Normal values for aortic diameters in children and adolescents-assessment in vivo by contrast-enhanced CMR-angiography. J Cardiovasc Magn Reson. 2008; 10:56.

22. Mohiaddin RH, Schoser K, Amanuma M, Burman ED, Longmore DB. MR imaging of age-related dimensional changes of thoracic aorta. J Comput Assist Tomogr. 1990; 14:748-52.

23. Sievers $\mathrm{HH}$, Onnasch DG, Lange PE, Bernhard A, Heintzen PH. Dimensions of the great arteries, semilunar valve roots, and right ventricular outflow tract during growth: normative angiocardiographic data. Pediatr Cardiol. 1983; 4:189-96.

24. Senzaki H, Akagi M, Hishi T, Ishizawa A, Yanagisawa M, Masutani S, Kobayashi T, Awa S. Age-associated changes in arterial elastic properties in children. Eur J Pediatr. 2002; 161:547-51.

25. Avolio AP, Chen SG, Wang RP, Zhang CL, Li MF, O'Rourke MF. Effects of aging on changing arterial compliance and left ventricular load in a northern Chinese urban community. Circulation. 1983; 68:50-8.

26. Jo CO, Lande MB, Meagher CC, Wang H, Vermilion RP. A simple method of measuring thoracic aortic pulse wave velocity in children: methods and normal values. J Am Soc Echocardiogr. 2010; 23:735-40.

27. Grotenhuis HB, Westenberg JJ, Steendijk P, van der Geest RJ, Ottenkamp J, Bax JJ, Jukema JW, de Roos A. Validation and reproducibility of aortic pulse wave velocity as assessed with velocity-encoded MRI J Magn Reson Imaging. 2009; 30:521-6.

28. Glukhova MA, Frid MG, Koteliansky VE. Phenotypic changes of human aortic smooth muscle cells during development and in the adult vessel. Am J Physiol. 1991; 261:78-80

29. Marty CN, Greenwald SE. Impaired synthesis of elastin in walls of aorta and large conduit arteries during early development as an initiating event in pathogenesis of systemic hypertension. Lancet. 1997; 350:953-5.

30. Nichols WW, O'Rourke MF: Aging, high blood pressure and disease in humans. In: McDonald's blood flow in arteries. London: Edward Arnold; 1990: p. $398-420$.

31. Rerkpattanapipat P, Hundley WG, Link KM, Brubaker PH, Hamilton CA, Darty SN, Morgan TM, Kitzman DW. Relation of aortic distensibility determined by magnetic resonance imaging in patients $>$ or $=60$ years of age to systolic heart failure and exercise capacity. Am J Cardiol. 2002; 90:1221-5.

32. Sharma J, Friedman D, Dave-Sharma S, Harbison M. Aortic distensibility and dilation in Turner's syndrome. Cardiol Young. 2009: 19:568-72.

33. Meyer AA, Kundt G, Steiner M, Schuff-Werner P, Kienast W. Impaired flowmediated vasodilation, carotid artery intima-media thickening, and elevated endothelial plasma markers in obese children: the impact of cardiovascular risk factors. Pediatrics. 2006; 117:1560-7.

\section{doi:10.1186/1532-429X-14-77}

Cite this article as: Voges et al:: Normal values of aortic dimensions, distensibility, and pulse wave velocity in children and young adults: a cross-sectional study. Journal of Cardiovascular Magnetic Resonance 2012 $14: 77$.

\section{Submit your next manuscript to BioMed Central and take full advantage of:}

- Convenient online submission

- Thorough peer review

- No space constraints or color figure charges

- Immediate publication on acceptance

- Inclusion in PubMed, CAS, Scopus and Google Scholar

- Research which is freely available for redistribution 